\title{
EFFECTS OF DEGRADABLE MULCHING FILM ON SOIL TEMPERATURE, SEED GERMINATION AND SEEDLING GROWTH OF DIRECT-SEEDED RICE (ORYZA SATIVA L.)
}

\author{
LI, H. ${ }^{1}$ - ZENG, S. ${ }^{2}-$ LUO, X. W. $.^{1,2}-$ ZANG, Y. $^{2}-$ LIANG, Z. H. ${ }^{2}-$ LI, X. L. ${ }^{3}-$ TENG, S. Z. ${ }^{3}-$ \\ YANG, W. W. ${ }^{*}$ \\ ${ }^{1}$ College of Biological and Agricultural Engineering, Jilin University, No.5988 Renmin Street, \\ 130022 Changchun, P.R. China
}

${ }^{2}$ Key Laboratory of Key Technology on Agricultural Machine and Equipment, Ministry of Education, South China Agricultural University, No.483 Wushan Road, 510642 Guangzhou, P.R. China

${ }^{3}$ Jalaid Banner Agricultural Technology Extension Center, 137600 Jalaid Banner, P.R. China

${ }^{*}$ Corresponding author

e-mail: yangwenwu@scau.edu.cn

(Received 28 $8^{\text {th }}$ Jul 2020; accepted $6^{\text {th }}$ Oct 2020)

\begin{abstract}
The effect of degradable mulching film on dry direct- seeded rice remains largely unknown. Then the aim of this research is to investigate the effects of degradable mulching film on dry direct-seeded rice. A field investigation of four treatments (CK: non-mulching; MF1: a degradable film (Shanghai Hongrui Biotech, Shanghai, China); MF2: a degradable film (Xifeng Plastic Corp. Ltd., Baishan, China); MF3: common agricultural mulching film (Jialiming New Material Corp Ltd., Hinggan League, China)) was conducted to evaluate the effects of degradable mulching film on the rice seed germination, seedling growth, soil temperature, and grain yield of dry direct-seeded rice. The results showed that compared to CK, mulching film treatments increased soil temperature, especially at night time, improved seed germination rate, plant height, leaf area of seedlings, and grain yield. MF1 showed good degradation performances and had the highest soil temperature at the night time of $13.65^{\circ} \mathrm{C}-14.08{ }^{\circ} \mathrm{C}$, grain yield at $7.938 \mathrm{tha}^{-1}$, and seedling growth with shoot dry mass at $46.73 \mathrm{mg}^{-\mathrm{plant}^{-1}}$ and root dry mass at $31.34 \mathrm{mg}$ plant $^{-1}$. The germination rate significantly increased by $6.99 \%-755.60 \%$ at MF1 as compared to CK. Overall, mulching films resulted in high yield due to the increasing soil temperature, seedling germination, and improving seedling growth, amongst MF1 performance the best.
\end{abstract}

Keywords: hill-drop drilling, grain yield, degradation progress, leaf area, root to shoot ratio

\section{Introduction}

Mulching film in the field provided a suitable microclimate for crop growth (DiazPerez et al., 2009; Namaghi et al., 2018; Zhang and Miles, 2020), enhanced the disaster resistance ability of crops and ultimately increased crop production ( $\mathrm{Bu}$ et al., 2013; O'Loughlin et al., 2017; Deschamps et al., 2019). The use of plastic film mulching allows for an early seeding date and a shortened germination time and increases the germination rate and the emergence rate, and achieves water-saving effects (Li et al., 2013; Biswas et al., 2015; Cosic et al., 2017). Especially, dry direct-seeded rice with mulching film could improve water utilisation rate, inhibit weeds growth, and improve soil temperature after sowing, which were conducive to high and stable yield (Towa et al., 2013; Fawibe et al., 2020). Traditional mulching film is polyethylene (PE), its application has caused environmental pollution and affected the food safety (Chae et al., 2018; Boots et al., 2019; 
$\mathrm{Hu}$ et al., 2020). Therefore, the use of degradable mulching film is essential for the development of future agriculture.

Previous studies have reported the application of biodegradable mulching films (Brodhagen et al., 2015; Moreno et al., 2017; Cozzolino et al., 2020). For example, the effects of biodegradable films on the production of peanut (Sun et al., 2018). The effect of mulching films on the biomass and soil organic matter mineralization and the yield of tomato has been evaluated (Moreno et al., 2008). A previous study has reported that biodegradable polymers improved root growth conditions and fruit quality of tomato (Sekara et al., 2019). The biodegradable paper mulching increased the yield of tomato and improved the fruit quality due to reduced nitrate but increased vitamin C (Zhang et al., 2019a). It has been reported that degradable mulching films affect the corn production and that degradable mulching films have comparable temperature conservation and water retention effects in response to common mulching films (Yang et al., 2010). Besides, previous report has indicated that the corn yield with biodegradable mulching film was similar to that with common mulching film and the biodegradable mulching film was sufficiently degraded after crop harvest $(\mathrm{Hu}, 2015)$. Research has shown that there were no significant differences in yields of Brassica chinensis L. among the degradable films, but the yield under degradable films was increased by $80 \%$ as compared to that with the non-mulching film and by $50 \%$ compared to that of common mulching film, and the natural protein, soluble sugar, and other components in B. chinensis L. were adequately improved (Shi et al., 2012). The effect of biodegradable film mulching on the production test of winter oilseed rape has been investigated and results showed that no significant difference in the average yield and water use efficiency in degradable film mulching were detected, whilst degradable film mulching showed higher seed quality than PE (Gu et al., 2017). Moreover, Bilck et al. (2010) have reported the effects of biodegradable mulching film on the production and quality of strawberry. Further study about the degradable film mulching on crop growth and development is still needed.

The effect of the application of degradable mulching film on the growth and yield of many crops such as tomato, corn, strawberry has been studied. Few studies have been conducted to evaluate the effect of degradable mulching film on the rice grown and yield. In this study, a field experiment was conducted to evaluate the degradable mulching film on the rice seed germination, seedling growth, soil temperature, and grain yield of directseeded rice. The results of this study may provide a basis and reference for the application of degradable mulching film in the rice field.

\section{Materials and methods}

\section{Description of study field}

The experimental site is located at Wudaohezi Village, Haolibao Town, Jalaid Banner, Hinggan League, Inner Mongolia Autonomous Region, P.R. China (46 $35^{\prime} 43^{\prime \prime} \mathrm{N}$, $123^{\circ} 04^{\prime} 36^{\prime \prime} \mathrm{E} ; 174 \mathrm{~m}$ in altitude). It has a temperate continental monsoon climate. There is a large temperature difference between day and night. The average annual temperature is $4.4^{\circ} \mathrm{C}$; the average annual precipitation is $430 \mathrm{~mm}$, with the precipitation is primarily concentrated from June to August. The average frost-free period is $130 \mathrm{~d}$. The site has a meadow soil type with deep and thick layers, and upon tillage, it is finely broken with a flat surface. The mass fraction of organic matter in the plough layer was $22.36 \mathrm{~g} / \mathrm{kg}$, and the $\mathrm{pH}$ of the topsoil was 5.89 . 


\section{Mulching film performance}

In this study, three types of mulching film, MF1: a degradable film (Shanghai Hongrui Biotech, Shanghai, China), MF2: a degradable film (Xifeng Plastic Corp. Ltd., Baishan, China), and MF3: a common agricultural mulching film (Jialiming New Material Corp Ltd., Hinggan League, China), were used. The performance measurements of each mulching film were repeated three times. The transmittance is an important index of optical performance that determined the amount of solar energy absorbed by the soil. In this study, transmittance/fog tester is used (Brand: Shanghai Shenguang Instrument \& Meter Co., LTD.; Model Number: WGT-S; Division value: 0.01\%). The light transmittance was in trend of MF1>MF3>MF2. Microcomputer controlled electronic universal material testing machine (Brand: Shanghai Hengyi Precision Instrument Co., LTD.; Model No.: Hy-0580; Maximum load: 500 N; Precision grade: 0.5 magnitudes) was used to detect the film tensile strength, elongation, and elastic modulus. The tensile strength and modulus of elasticity in MF2 and MF3 are better than that of MF1. The elongation of MF1 and MF3 was superior to that of MF2. (as shown in Table 1).

Table 1. The properties of Mulching film

\begin{tabular}{c|c|c|c|c}
\hline Mulch & $\begin{array}{c}\text { Transmittance } \\
(\boldsymbol{\%})\end{array}$ & $\begin{array}{c}\text { Tensile Strength } \\
(\mathbf{M p a})\end{array}$ & $\begin{array}{c}\text { Elongation } \\
(\boldsymbol{\%})\end{array}$ & $\begin{array}{c}\text { Elastic Modulus } \\
(\mathbf{M p a})\end{array}$ \\
\hline MF1 & $6.48 \mathrm{~A}$ & $9.51 \mathrm{~B}$ & $278.45 \mathrm{~B}$ & $148.80 \mathrm{~B}$ \\
MF2 & $0.58 \mathrm{C}$ & $10.51 \mathrm{AB}$ & $93.64 \mathrm{C}$ & $297.39 \mathrm{~A}$ \\
MF3 & $4.50 \mathrm{~B}$ & $11.90 \mathrm{~A}$ & $469.28 \mathrm{~A}$ & $263.27 \mathrm{~A}$ \\
\hline
\end{tabular}

Different uppercase letters followed by the same column among the treatments means significant differences $(\mathrm{p}<0.01)$ according to LSD. MF1: a degradable film (Shanghai Hongrui Biotech, Shanghai, China); MF2: a degradable film (Xifeng Plastic Corp. Ltd., Baishan, China); MF3: Common agricultural mulching film (Jialiming New Material Corp Ltd., Hinggan League, China)

\section{Experiment design}

Three mulching film treatments (MF1, MF2, and MF3) were carried in this experiment, and the non-mulching treatment was taken as control (CK). The three types of mulching film are black, with $0.01 \mathrm{~mm}$ in thick, and $1550 \mathrm{~mm}$ in wide. The planting pattern of "one film, two drip irrigation belts, and eight rows" (as shown in Fig. 1) was adopted, and all the field work was completed by a multi-functional machine that integrated film laying, seed sowing, and soil covering.

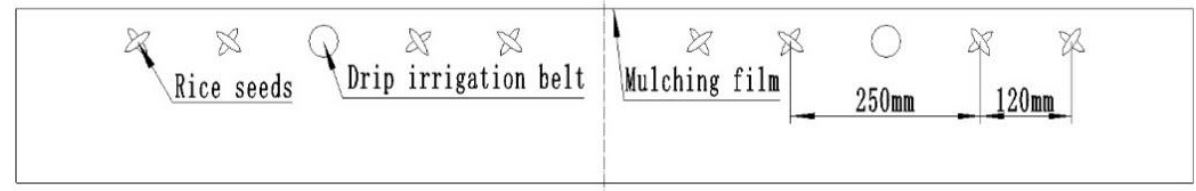

Figure 1. Planting pattern diagram

In the experiment, the length of each treatment was $50 \mathrm{~m}$, and each treatment was repeated 3 times, and the total plot area was $1250 \mathrm{~m}^{2}(50 \times 25 \mathrm{~m})$. The distance between treatments was $600 \mathrm{~mm}$ which was increased that the external influences and interactions between the treatments were reduced. During planting, wide and narrow row spacing was 
used in an alternating manner, with the narrow row spacing being $120 \mathrm{~mm}$ and the wide row spacing being $250 \mathrm{~mm}$. One drip irrigation belt was set in the middle of the wide row, which was shared by four rows.

The same water and fertilizer management were used in the four treatments, which was consistent with local field management. The pump station was used to supply water and fertilizer in equal amounts through drip irrigation belts, and the time of water and fertilizer application was recorded. On April 10, 2019, base fertilizer was applied, and the fertilizer was mixed fertilizer $(\mathrm{N}: \mathrm{P}: \mathrm{k}=12: 18: 15)$ of $150 \mathrm{kgha}^{-1}$ and biological fungus fertilizer of $150 \mathrm{~kg} \mathrm{ha}^{-1}$. Topdressing twice during the growth cycle: June 5 (urea: $37.5 \mathrm{~kg} \mathrm{ha}^{-1}$, liquid fertilizer (high nitrogen type): $22.5 \mathrm{~kg} \mathrm{ha}^{-1}$ ) and June 20 (liquid fertilizer (high potassium type): $22.5 \mathrm{~kg} \mathrm{ha}^{-1}$ ). According to the growth stage of rice and weather conditions to determine the time and amount of water supply. In the mulching treatments, manual weeding was used, while the combination of mechanical and herbicide weeding was applied in the non-mulching treatment.

The tested rice variety was Suijing 18, which covers the largest local cultivation area. It has a growth period of $135 \mathrm{~d}$. The technique of seeding in dry soil and drip irrigation for emergence was adopted. The seeds were sown on April 29, 2019, and 15 \pm 3 seeds were sown per hill with a hill spacing of $120 \mathrm{~mm}$; and the plants were harvested on September 25-28, 2019. The degradation progress of mulching film was observed until the next sowing season (April 15, 2020).

\section{Sampling and measurement}

\section{Soil temperature}

The soil temperature at different soil depths for each treatment was measured by a set of sensors (Manufacturer: Sonbest Company of Shanghai; Model Number: KM3002B; Configuration: three probes), which were installed in the soil at 5, 10, and $15 \mathrm{~cm}$ below the ground surface. The system collected and storaged data automaticly at intervals of $30 \mathrm{~min}$.

\section{Germination rate}

The germination rate is an important basis for guaranteeing that a crop has full germination with a single sowing, and it can reflect the effects of different treatments on germination. After the first water supply, the rice seeds would readily have the appropriate germination conditions. After $5 \mathrm{~d}$ of water treatment, the germination condition was closely monitored. For each treatment, 10 hills of plants were selected to determine the germination rate, which was recorded once a day until the germination rate of the all treatments was stable; the germination rate for each treatment was rendered as the final germinate rate.

$$
\text { Germination rate }(\%)=\text { number of buds } / \text { number of seeds } \times 100 \%
$$

\section{Plant height and leaf area}

The plant height and leaf area are the most commonly used indicators for measuring the growth of rice seedlings at the seedling stage. At the three-leaf stage, 10 rice plants with uniform growth were selected for each treatment; their plant heights were measured using a steel ruler, and the leaf area of each plant was calculated using an LA-S series 
plant image analyser (Manufacturer: Wseen Ltd., Hangzhou, China; Model Number: LAS Series).

\section{Biomass}

The root and shoot biomass of rice plants were measured at the three-leaf stage. for each treatment, 10 rice seedlings with uniform growth were selected and excavated as a whole. They were washed and rinsed with water, air-dried, and then cut with scissors at the top of the root system. The plants were separately placed in a drying container, which was in turn placed in an electric thermostatic drying oven (Manufacturer: Shanghai Heheng Instrument \& Equipment Co., Ltd.; Model Number: DHG-9050A) at $105^{\circ} \mathrm{C}$ for fixation $(30 \mathrm{~min})$; next, the temperature was adjusted to $80{ }^{\circ} \mathrm{C}$ to dry the materials to a constant weight. The samples were weighed using a high-precision electronic balance (Model: Hengji Electronic Analytical Weighing Scale FA1204; Precision level: level 1; Range: 120 g; Division value: $0.1 \mathrm{mg}$ ).

\section{The degradation progress of mulching film}

Mulching film cannot degrade prematurely to affect the growth of rice seedlings, meanwhile, the degradation cycle cannot be too long to affect the planting of the next crop season. In this study, the degradation process was recorded and measured by visual assessment and picture comparison. The induction period, cracking period, major cracking period, fragmentation period, residue film entrainment at harvest, and the degradation of residue film under conventional tillage were recorded.

\section{Grain yield}

The grain yield was randomly harvested from three points $\left(1 \mathrm{~m}^{2}\right)$ for each treatment. After artificial threshing, electronic scale is used to weigh the rice grains, and then the average value of the three points is calculated, which is the grain yield under this treatment.

\section{Statistical analysis}

Data processing (the analysis of variance (ANOVA) and correlation coefficients) were performed using Microsoft Excel and Design Expert software. The differences amongst means separated by using the least significant difference (LSD) test at 5\% significance level.

\section{Results}

\section{Soil temperature}

MF1 showed higher in the soil temperature at the $5 \mathrm{~cm}$ depth as compared to CK. A higher in the soil temperature at the $5 \mathrm{~cm}$ depth from 7:00-22:00 was detected at MF2 when compared to CK. MF3 showed lower in the soil temperature at the $5 \mathrm{~cm}$ depth from 7:00-16:00 but higher in the soil temperature at the $5 \mathrm{~cm}$ depth from 16:00-7:00. Compared with CK, MF1 and MF2 showed higher in the soil temperature at the 10 and $15 \mathrm{~cm}$ depth. MF3 showed lower in the soil temperature from 7:00-16:00 and 8:00-17:00 at 10 and $15 \mathrm{~cm}$ depth than CK, respectively. Compared with CK, higher in the soil 
temperature from 16:00-7:00 and 17:00-8:00 at 10 and $15 \mathrm{~cm}$ depth was detected for MF3 (Figure 2).

A)

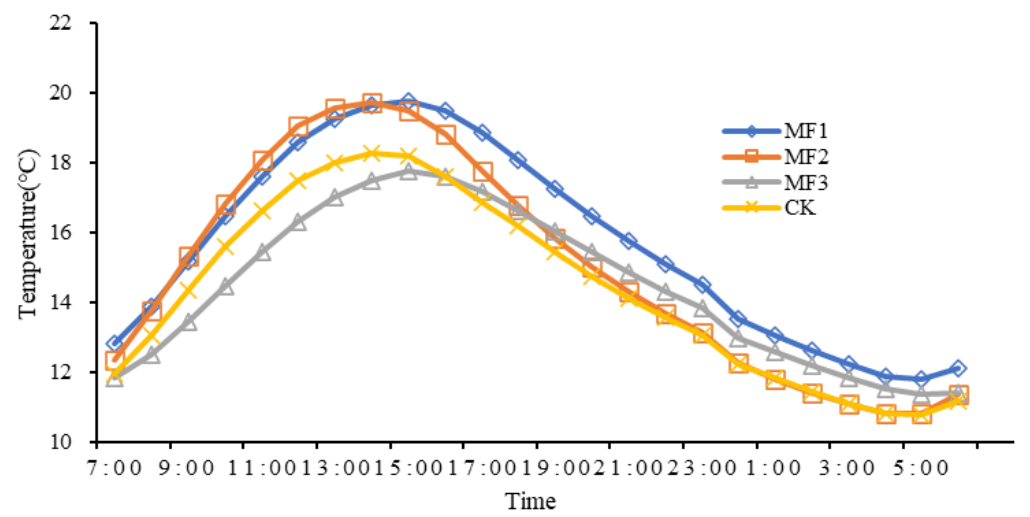

B)

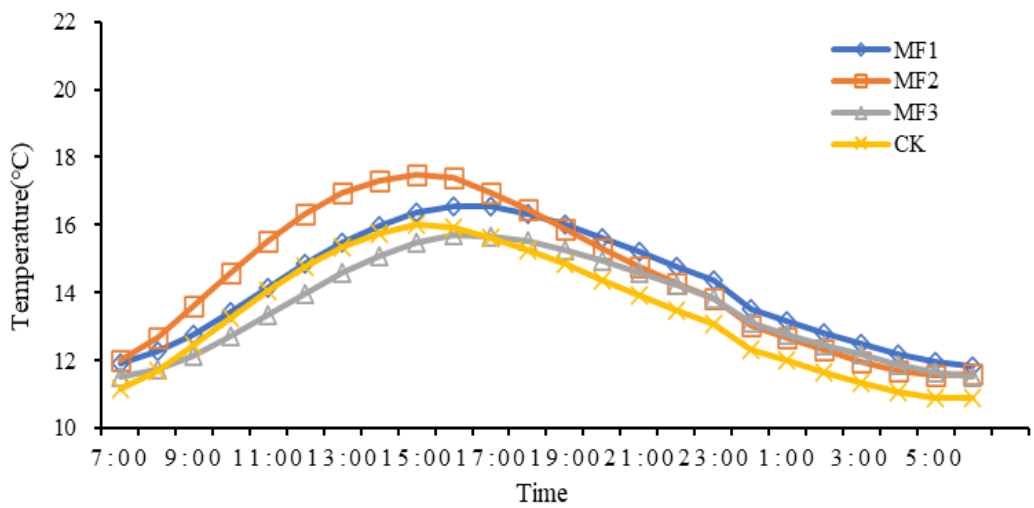

C)

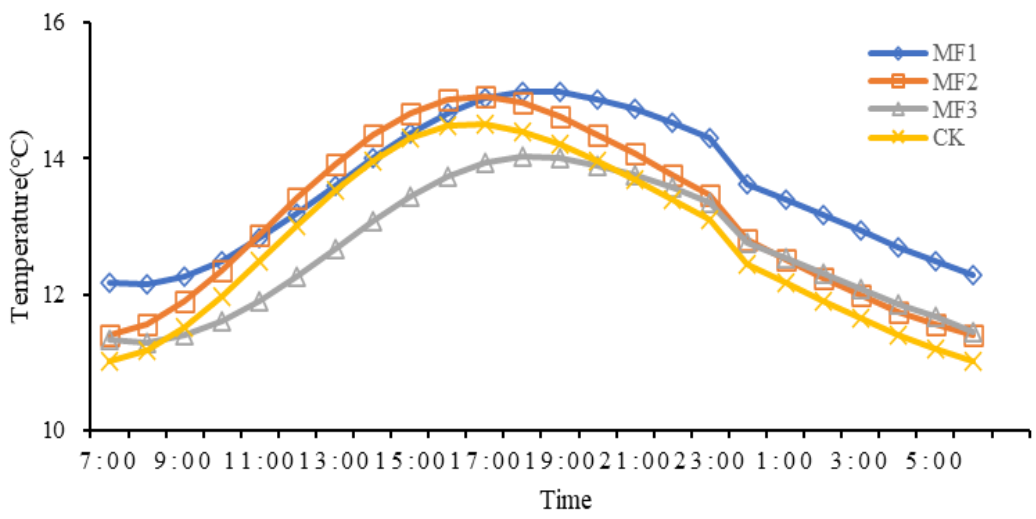

Figure 2. Changes of the daily soil temperature in soil depth of $5 \mathrm{~cm}(A), 10 \mathrm{~cm}(B)$, and $15 \mathrm{~cm}$ (C). CK: Non-mulching; MF1: a degradable film (Shanghai Hongrui Biotech, Shanghai, China); MF2: a degradable film (Xifeng Plastic Corp. Ltd., Baishan, China); MF3: Common agricultural mulching film (Jialiming New Material Corp Ltd., Hinggan League, China)

From 8:00-18:00, compared with CK, MF1, and MF2 significantly increased the average soil temperature at $5 \mathrm{~cm}$ depth by $7.63 \%$ and $7.42 \%$, respectively. The average soil temperature at $10 \mathrm{~cm}$ depth significantly increased by $9.58 \%$ at MF2 as compared to CK. No significant difference was detected in the average soil temperature at $15 \mathrm{~cm}$ depth among the treatments (Table 2). 
Table 2. The average soil temperature under different treatments

\begin{tabular}{c|c|c|c|c|c|c}
\hline \multirow{2}{*}{ Treatment } & \multicolumn{2}{|c|}{ Temperature $\left({ }^{\circ} \mathbf{C}\right)$ during 8:00-18:00 } & \multicolumn{3}{c}{ Temperature $\left({ }^{\circ} \mathbf{C}\right) \mathbf{d u r i n g} \mathbf{1 8 : 0 0 - 8 : 0 0}$} \\
\cline { 2 - 7 } & $\mathbf{5} \mathbf{~ c m}$ & $\mathbf{1 0} \mathbf{~ c m}$ & $\mathbf{1 5} \mathbf{~ c m}$ & $\mathbf{5} \mathbf{~ c m}$ & $\mathbf{1 0} \mathbf{~ c m}$ & $\mathbf{1 5} \mathbf{~ c m}$ \\
\hline MF1 & $17.862 \mathrm{a}$ & $14.84 \mathrm{~b}$ & $13.451 \mathrm{a}$ & $14.077 \mathrm{a}$ & $13.732 \mathrm{a}$ & $13.653 \mathrm{a}$ \\
MF2 & $17.826 \mathrm{a}$ & $15.882 \mathrm{a}$ & $13.482 \mathrm{a}$ & $12.894 \mathrm{bc}$ & $13.387 \mathrm{a}$ & $12.911 \mathrm{~b}$ \\
MF3 & $15.912 \mathrm{~b}$ & $14.036 \mathrm{c}$ & $12.534 \mathrm{~b}$ & $13.34 \mathrm{~b}$ & $13.249 \mathrm{a}$ & $12.755 \mathrm{~b}$ \\
CK & $16.596 \mathrm{~b}$ & $14.493 \mathrm{bc}$ & $13.096 \mathrm{ab}$ & $12.738 \mathrm{c}$ & $12.595 \mathrm{~b}$ & $12.54 \mathrm{~b}$ \\
\hline
\end{tabular}

Different lowercase letters followed by the same column among the treatments means significant differences ( $\mathrm{p}<0.05$ ) according to LSD. CK: Non-mulching; MF1: a degradable film (Shanghai Hongrui Biotech, Shanghai, China); MF2: a degradable film (Xifeng Plastic Corp. Ltd., Baishan, China); MF3: Common agricultural mulching film (Jialiming New Material Corp Ltd., Hinggan League, China)

From 18:00-8:00, the average temperature in the soil at $5 \mathrm{~cm}$ depth significantly increased by $10.51 \%$ and $4.73 \%$ at MF1 and MF3 as compared to CK, respectively. Compared with $\mathrm{CK}, \mathrm{MF} 1, \mathrm{MF} 2$, and MF3 significantly increased the average temperature in the soil at $10 \mathrm{~cm}$ depth by $9.03 \%, 6.29 \%$, and $5.19 \%$, respectively. The average temperature in the soil at $15 \mathrm{~cm}$ depth significantly increased by $8.86 \%$ at MF1 as compared with CK (Table 2).

\section{Germination rate}

Compared with CK, significantly increased germination rate by $213.02 \%$ was detected at MF1 on 10 May. On 12 May, the germination rate significantly increased by $755.60 \%$, $450.71 \%$, and $621.54 \%$ at MF1, MF2, and MF3, respectively as compared to CK. Significantly increased in the germination rate at MF1, MF2, and MF3 were detected on 13 May (increased by 331.26\%-378.49\%), 14 May (increased by 20.97\%-22.13\%), 15 May (up to 8.63\%), and 16 May (up to 6.99\%) (Figure 3).

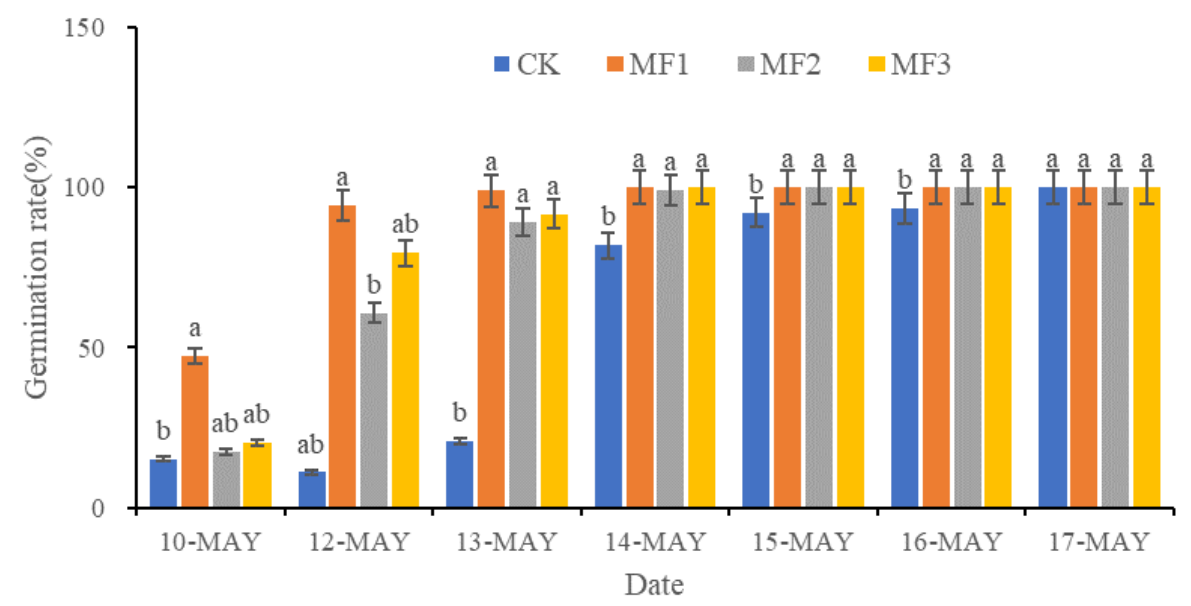

Figure 3. The germination rate under different treatment. Different lowercase letters above bars indicated that there were significant differences ( $p<0.05)$ according to LSD. CK: Nonmulching; MF1: a degradable film (Shanghai Hongrui Biotech, Shanghai, China); MF2: a degradable film (Xifeng Plastic Corp. Ltd., Baishan, China); MF3: Common agricultural mulching film (Jialiming New Material Corp Ltd., Hinggan League, China) 


\section{Seedling growth}

The plant heights significantly increased by $46.88 \%, 57.29 \%$, and $41.67 \%$ at MF1, MF2, and MF3 as compared to CK, respectively (Figure 4). The leaf areas significantly increased by $26.12 \%, 25.64 \%$, and $30.64 \%$ at MF1, MF2, and MF3 as compared to CK, respectively (Figure 5). MF1 had the highest dry mass in the shoot $\left(46.73 \mathrm{mg} \mathrm{plant}^{-1}\right.$ ) and root (31.34 $\left.\mathrm{mg} \mathrm{plant}^{-1}\right)$, whilst no significant difference in shoot biomass, root biomass, and root to shoot ratio was detected (Figures 6-8).

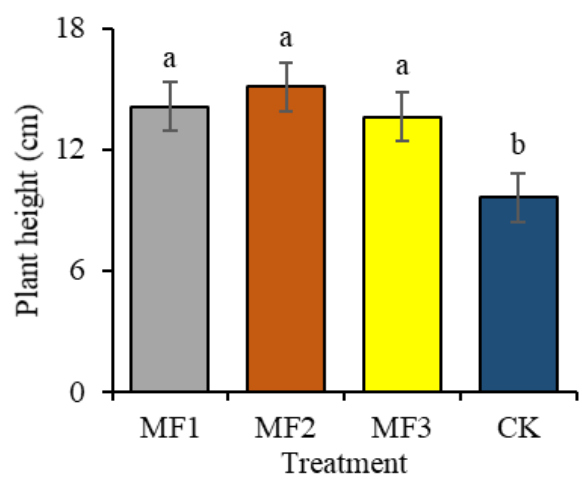

Figure 4. The plant height of seedling under different treatments. Different lowercase letters above bars indicated that there were significant differences ( $p<0.05)$ according to LSD. CK: Non-mulching; MF1: a degradable film (Shanghai Hongrui Biotech, Shanghai, China); MF2: a degradable film (Xifeng Plastic Corp. Ltd., Baishan, China); MF3: Common agricultural mulching film (Jialiming New Material Corp Ltd., Hinggan League, China)

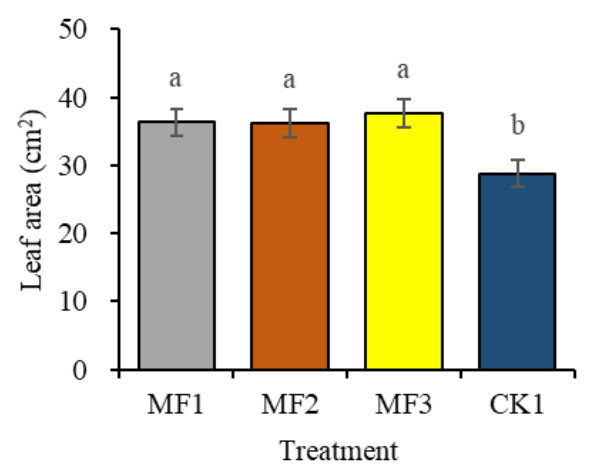

Figure 5. The leaf area of seedling under different treatments. Different lowercase letters above bars indicated that there were significant differences ( $p<0.05)$ according to LSD. CK: Nonmulching; MF1: a degradable film (Shanghai Hongrui Biotech, Shanghai, China); MF2: a degradable film (Xifeng Plastic Corp. Ltd., Baishan, China); MF3: Common agricultural mulching film (Jialiming New Material Corp Ltd., Hinggan League, China)

\section{Grain yield}

The highest grain yield was detected at MF1 (7.938 $\left.\mathrm{t} \mathrm{ha}^{-1}\right)$. The grain yield was increased by $11.83 \%, 4.82 \%$, and $5.73 \%$ at MF1, MF2, and MF3 as compared to CK, respectively (Figure 9). 


$$
-8241 \text { - }
$$

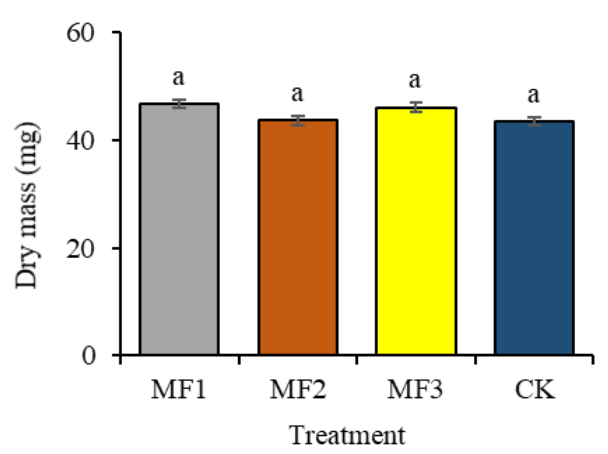

Figure 6. The aboveground dry mass of seedling under different treatments. Different lowercase letters above bars indicated that there were significant differences $(p<0.05)$ according to LSD. CK: Non-mulching; MF1: a degradable film (Shanghai Hongrui Biotech, Shanghai, China); MF2: a degradable film (Xifeng Plastic Corp. Ltd., Baishan, China); MF3:

Common agricultural mulching film (Jialiming New Material Corp Ltd., Hinggan League, China)

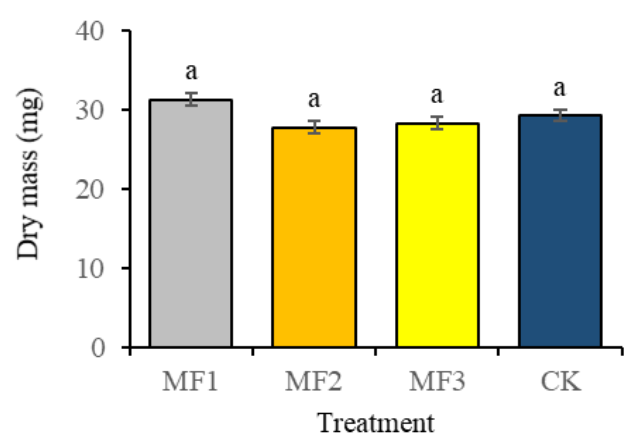

Figure 7. The root dry mass of seedling under different treatments. Different lowercase letters above bars indicated that there were significant differences ( $p<0.05)$ according to LSD. CK: Non-mulching; MF1: a degradable film (Shanghai Hongrui Biotech, Shanghai, China); MF2: a degradable film (Xifeng Plastic Corp. Ltd., Baishan, China); MF3: Common agricultural mulching film (Jialiming New Material Corp Ltd., Hinggan League, China)

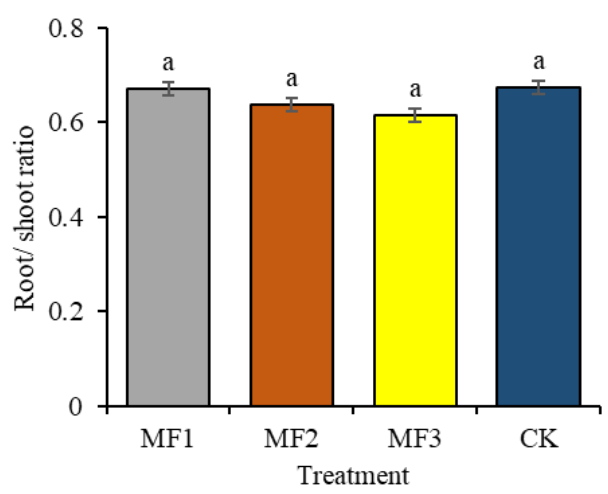

Figure 8. The root/shoot ratio of seedling under different treatments. Different lowercase letters above bars indicated that there were significant differences ( $p<0.05)$ according to LSD. CK: Non-mulching; MF1: a degradable film (Shanghai Hongrui Biotech, Shanghai, China); MF2: a degradable film (Xifeng Plastic Corp. Ltd., Baishan, China); MF3: Common agricultural mulching film (Jialiming New Material Corp Ltd., Hinggan League, China) 


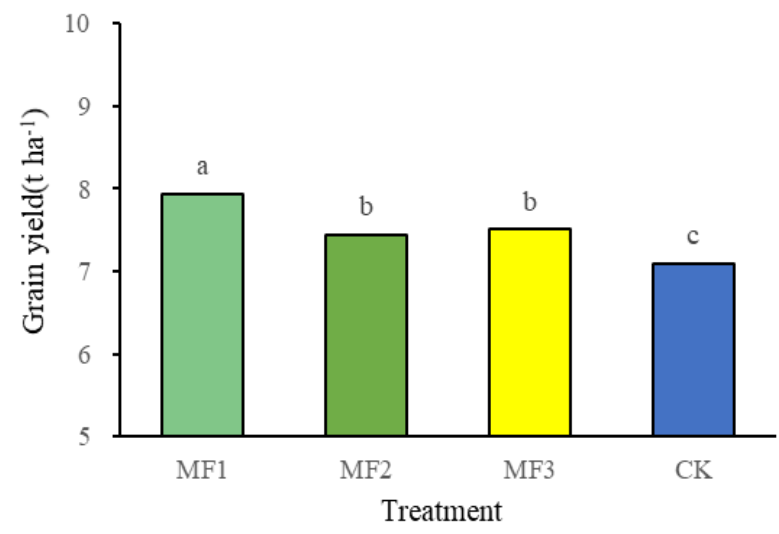

Figure 9. The grain yield under different treatments. CK: Non-mulching; MF1: a degradable film (Shanghai Hongrui Biotech, Shanghai, China); MF2: a degradable film (Xifeng Plastic

Corp. Ltd., Baishan, China); MF3: Common agricultural mulching film (Jialiming New Material Corp Ltd., Hinggan League, China)

\section{The degradation progress of mulching film}

The induction period for MF1 and MF2 was 19-June and 28-June, respectively. The cracking period for MF1 and MF2 was 28-June and 7-July, respectively. A similar major cracking period and fragmentation period were detected for MF1 and MF2. Both MF1 and MF2 showed good degradation performances. MF3 showed no degradation (Table 3).

Table 3. The degradation progress of mulching film in field

\begin{tabular}{|c|c|c|c|}
\hline Period & MF1 & MF2 & MF3 \\
\hline Induction period & June 19 & June 28 & - \\
\hline Cracking period & June 28 & July 7 & - \\
\hline Major cracking period & September 7 & September 7 & - \\
\hline Fragmentation period & September 17 & September 17 & - \\
\hline Residue film entrainment at harvest & No entrainment & No entrainment & No entrainment \\
\hline $\begin{array}{l}\text { Degradation of residue film under } \\
\text { conventional tillage }\end{array}$ & Good degradation & Good degradation & No degradation \\
\hline
\end{tabular}

MF1: a degradable film (Shanghai Hongrui Biotech, Shanghai, China); MF2: a degradable film (Xifeng Plastic Corp. Ltd., Baishan, China); MF3: common agricultural mulching film (Jialiming New Material Corp Ltd., Hinggan League, China)

\section{Correlation analysis}

The germination rate on 10 May was significantly positively related to the mean temperature at $5 \mathrm{~cm}$ depth in the soil from 18:00-8:00 and the mean temperature at $15 \mathrm{~cm}$ depth in the soil from 18:00-8:00. The plant height is highly related to the germination rate on 14-May, 15-May, and 16-May. The leaf area is highly related to the germination rate on 13-May 14-May, 15-May, and 16-May (Table 4). 
Table 4. Correlation analysis between the investigated parameters

\begin{tabular}{|c|c|c|c|c|c|c|c|c|c|c|c|c|c|c|c|c|}
\hline Index & V001 & V002 & V003 & V004 & V005 & V006 & V007 & V008 & V009 & V010 & V011 & V012 & V013 & V014 & V015 & V016 \\
\hline V002 & 0.7059 & & & & & & & & & & & & & & & \\
\hline V003 & 0.5390 & 0.9598* & & & & & & & & & & & & & & \\
\hline V004 & 0.4664 & 0.9414 & $0.9962 * *$ & & & & & & & & & & & & & \\
\hline V005 & 0.4410 & 0.9254 & $0.9935 * *$ & $0.9987 * *$ & & & & & & & & & & & & \\
\hline V006 & 0.4410 & 0.9254 & $0.9935 * *$ & $0.9987 * *$ & $1.0000 * *$ & & & & & & & & & & & \\
\hline V007 & 0.7859 & 0.8488 & 0.6709 & 0.6388 & 0.6000 & 0.6000 & & & & & & & & & & \\
\hline V008 & 0.8700 & 0.2894 & 0.0574 & -0.0247 & -0.0560 & -0.0560 & 0.5767 & & & & & & & & & \\
\hline V009 & 0.3809 & -0.3781 & -0.5129 & -0.5846 & -0.5906 & -0.5906 & -0.1456 & 0.7240 & & & & & & & & \\
\hline V010 & 0.3622 & 0.8250 & 0.9476 & $0.9526 *$ & $0.9661 *$ & $0.9661 *$ & 0.4019 & -0.1390 & -0.5282 & & & & & & & \\
\hline V011 & 0.3862 & 0.9230 & $0.9770 *$ & $0.9903 * *$ & 0.9869* & 0.9869* & 0.6441 & -0.1009 & -0.6788 & 0.9195 & & & & & & \\
\hline V012 & 0.5101 & 0.2720 & 0.3444 & 0.2911 & 0.3147 & 0.3147 & -0.0407 & 0.3462 & 0.4302 & 0.4867 & 0.1581 & & & & & \\
\hline V013 & -0.0204 & 0.0254 & 0.2358 & 0.2275 & 0.2715 & 0.2715 & -0.4502 & -0.2249 & 0.0842 & 0.5091 & 0.1320 & 0.8321 & & & & \\
\hline V014 & 0.3836 & 0.0255 & 0.0957 & 0.0412 & 0.0677 & 0.0677 & -0.2346 & 0.3369 & 0.5854 & 0.2649 & -0.0941 & $0.9674 *$ & 0.8273 & & & \\
\hline V015 & $0.9551 *$ & 0.8403 & 0.6701 & 0.6139 & 0.5824 & 0.5824 & 0.9309 & 0.7564 & 0.1237 & 0.4489 & 0.5681 & 0.3041 & -0.1870 & 0.1303 & & \\
\hline V016 & 0.7559 & 0.9407 & 0.9406 & 0.9084 & 0.9044 & 0.9044 & 0.6890 & 0.3372 & -0.1919 & 0.8837 & 0.8473 & 0.5810 & 0.3298 & 0.3594 & 0.8000 & \\
\hline V017 & $0.9628 *$ & 0.7655 & 0.6667 & 0.5994 & 0.5858 & 0.5858 & 0.6962 & 0.7381 & 0.2907 & 0.5603 & 0.5046 & 0.6817 & 0.2284 & 0.5342 & 0.9043 & 0.8732 \\
\hline
\end{tabular}

$*$ and ** significant at 0.05 and 0.01 level, respectively.

V001: germination rate on 10-May; V002: germination rate on 12-May; V003: germination rate on 13-May; V004: germination rate on 14-May; V005: germination rate on 15-May; V006: germination rate on 16-May; V007: aboveground dry mass; V008: root dry mass; V009: root/shoot ratio; V010: plant height; V011: leaf area; V012: mean temperature at $5 \mathrm{~cm}$ depth in soil during 8:00-18:00; V013: mean temperature at $10 \mathrm{~cm}$ depth in soil during 8:00-18:00; V014: mean temperature at 15 $\mathrm{cm}$ depth in soil during 8:00-18:00; V015: mean temperature at $5 \mathrm{~cm}$ depth in soil during 18:00-8:00; V016: mean temperature at 10 $\mathrm{cm}$ depth in soil during 18:008:00; V017: mean temperature at $15 \mathrm{~cm}$ depth in soil during 18:00-8:00 


\section{Discussion}

The effect of degradable and traditional mulching films on soil temperature has been widely documented. Generally, the degradable mulching film and PE mulching film have similar effects of increasing soil temperature at crop early growth stages. For example, Shen et al. $(2012,2019)$ reported that in the early period of maize growth, the degradable films had good warming effects on soil, which were similar with the plastic film. The degradable films fulfilled successfully all the functions of the plastic film, thus they were recommended as viable option to the plastic film due to their good degradability. Zhang et al. (2020) reported that biodegradable plastic film mulching increased the soil temperature at soil depths of $5 \mathrm{~cm}, 15 \mathrm{~cm}$, and $25 \mathrm{~cm}$, over the maize's entire growth period, by $3.1{ }^{\circ} \mathrm{C}-3.2{ }^{\circ} \mathrm{C}$ in 2017 and $1.2{ }^{\circ} \mathrm{C}-2.1{ }^{\circ} \mathrm{C}$ in 2018 compared with the nonmulched treatment. This study shows that biodegradable plastic film could be used as a substitute for common plastic film (Zhang et al., 2020). But, previous study reported that the soil temperature under degradable mulch was higher than that of $\mathrm{PE}$ mulch (Subrahmaniyan et al., 2008), which was maybe related to the transmittance of mulch. The amount of heat exchange and radiation at night was related to the mulch materials, as the description of previous studies (Sekara, 2019). Therefore, in the present study showed that MF1 degradable film and the PE plastic film had good warming effects on soil in the early period of rice growth, but the increased temperature performance of degradable mulching films at the $5 \mathrm{~cm}, 10 \mathrm{~cm}$, and $15 \mathrm{~cm}$ soil depths outperformed that of PE mulching film and the non-mulching treatment (Table 2, Figure 2). Both degradable mulching film and PE mulching film had the effect of raising soil temperature, especially the thermal insulation effect at night promoted the germination of rice seeds and affected the growth of seedlings. Previous study reported that degradable mulch could significantly improve the temperature of soil tillage layer and promote plant growth and development. The grain yields for degradable films No.2, No.1, and No.3 which had different degradation cycles were significantly improved, and with no significant difference between degradable films and the plastic film (Shen et al., 2019). Previous study found that the night temperature of biodegradable mulch was higher than that of ordinary mulch, promoting the growth of crops (Zhang et al., 2016). Yin et al. (2012) described that biodegradable film mulching could significantly improve the temperature of soil tillage layer, with better thermal insulation performance, and was conducive to the growth and development of crops in the early stage. Alamro et al. (2019) reported that the current results showed that all mulching plot had significantly higher soil temperature than bare soil. The improvement of tomato plant growth was noticed mainly in leaf area, fresh and dry weight of shoot under biodegradable mulch treatment. Based on the results, the using of biodegradable mulch could perform similar and/or better than polyethylene mulch in term of tomato growth and yield, which could be adopted as a sustainable alternative to polyethylene mulch. Lopez-Tolentino et al. (2017) found that different plastic mulches impact positively on the yield of cucumber crop. The benefit in yield by the different plastic mulches in the conditions of this study was due to their soil warming ability that results in improved soil temperature, leaf area, and plant dry weight (LopezTolentino et al., 2017). In the present study, degradable mulching film showed better warming effect, which was due to its higher light transmittance. Meanwhile, MF1 had the highest soil temperature at the night time of $13.65^{\circ} \mathrm{C}-14.08{ }^{\circ} \mathrm{C}($ Table 2, Figure 2), which effectively extended the growth time of crops, and promoted rice germination and plant growth. The results of the present study were consistent with those of previous studies. 
MF1 degradable mulching film could be used as an alternative to PE mulching film due to the its similar properties in temperature.

As is known to all, temperature is an important factor affecting the germination of seeds. Mulching films increases the soil temperature and creates good conditions for seed germination. In this study, compared with CK, mulching film treatments increased soil temperature, especially at night time, which promoted the germination of seeds. Adamczewska-Sowinska and Sowinski (2020) reported that low soil and air temperatures hinder the germination of sweet maize seeds and their early growth. Similarly, previous study showed that degradable mulch has the same effect as PE plastic film, which promotes the germination and emergence of seeds and speeds up the growth process (Zhang, 2010). All of the researches were the same as the present study, in the present research both degradable mulching films and PE mulching film promoted the germination progress of rice seeds, and MF1 was $4 \mathrm{~d}$ earlier than that under the non-mulching treatment, and these effects may be due to the insulation and water retention of mulching films.

In the present study, the plant height, and leaf area of rice in the different mulching film treatments were higher than those in the bare soil, with no significant differences detected among the three mulching films. In this study, the positive effect of MF1 degradable mulching film on rice plant height, and leaf area in this region was comparable to that of the PE plastic film (Figures 4-8). These results are similar to previous studies, which have described that no significant differences were recorded in leaf area of seedling between degradable mulching films and common mulching film, whereas leaf area was lowest under the not mulched control. Moreover, degradable black mulching film N8 and common mulching film had the highest fruit yield, $77.8 \mathrm{t} / \mathrm{ha}$ on average, the not mulched control had the worst performance, 68.8 t/ha (Sekara et al., 2019). Zhang et al. (2019b) reported that the average plant height had no significant difference across all mulched treatments, but was greater than no mulch control. Furtherly, total fruit yield was greater across mulched treatments than the bare ground control. Zhang (2010) found that degradable mulch increased plant height and dry matter accumulation of crops, with no significant difference from normal mulching film. And the analysis of yield characteristic indicated that covered by normal mulching film and degradable film had great significance with bare land, but the influence of liquid film was not significant. Deng et al. (2019) found that both the biodegradable mulch film and the polyethylene plastic film significantly increased various physiological parameters, such as crop height, stalk diameter, and leaf area. And all the mulch film treatments significantly increased the yield of maize and cotton, but there was no significant difference among the three mulch film treatments. In this research, these mulching film treatments increased rice grain yield by 4.82-11.83\% as compared to $\mathrm{CK}$, due to mulching film treatments to promote the growth and health of plants, it was associated with the increase in rice grain yield. So, the present study was in agreement with previous studies.

The degradability of degradable mulching film is an important factor to be adopted. A lot of studies have been carried out on the degradation of degradable mulching film. Sintim et al. (2020) studied the degradation of different biodegradable plastic film in compost and soil. The results showed that the degradation performance of degradable plastic film was mainly affected by its physical and chemical properties. Meanwhile, the degradation rate of degradable plastic film in compost was faster than that in soil, the degradation rate in summer was greater than that in winter, and the degradation rate in rainy season was better than that in dry season. Yin et al. (2019) carried out a study on 
the effects of different degradation rates of biodegradable mulching film on soil environment and maize growth. The study showed that the degradation rate of biodegradable mulching film was affected by climate and crop species. For example, high temperature increased the degradation rate of biodegradable mulching film. Previous study reported that under controlled conditions, the aerobic biodegradation of Agrobiofilm ${ }^{\circledR} 1$ had an increase of $55.8 \%$ when comparing the continuous and the batch system, for 72 days of assay (Costa et al., 2014). In a maize experiment, Zhang et al. (2020) described that at the end of the growth period the degradation rates of biodegradable film 1,2 , and 3 were $35.2 \%, 19.7 \%$, and $18.1 \%$ in 2018 , respectively. In the current study, the two kinds of degradable mulching film showed good degradation performance (Table 3). There was no bulk mulching film residue during tillage and preparation, which had no effect on the tillage and the next sowing season. Meanwhile, the degradation cycles could meet the requirements of rice growth. The present results consistent with the ones achieved.

Overall, mulching film treatments affected the soil temperature, lead to changes in the germination rate, plant height and leaf area of seedlings, and ultimately affected the grain yield. MF1 showed good degradation performances and the highest soil temperature at night time, grain yield, germination rate, and seedling growth.

\section{Conclusions}

Mulching film treatments increased soil temperature at night time, germination rate, plant height and leaf area of seedlings, grain yield. MF1 showed good degradation performances and the highest soil temperature at night time, grain yield, germination rate, and seedling growth. So MF1 degradable mulching film could be considered as an alternative for the common agricultural mulching film.

Degradable mulching film has a positive effect on the growth and yield of rice. In the future, the trial area of degradable mulching film in rice cultivation should be expanded to further verify the feasibility of this technology and the adaptability to different soil conditions. Meanwhile, the influence of degradable mulching film on soil should be studied.

Acknowledgements. The work was supported by the Special Fund for Construction of Modern Agricultural Industry Technology System of China (CARS-01-41), and Special Projects in Key Area of 'Artificial Intelligence' of General Colleges and Universities in Guangdong Province (2019KZDZX1003).

\section{REFERENCES}

[1] Adamczewska-Sowinska, K., Sowinski, J. (2020): Reaction of Sweet Maize to the Use of Polyethylene Film and Polypropylene Non-Woven Fabric in the Initial Growth Phase. Agronomy 10(1): 141-155.

[2] Alamro, M., Mahadeen, A., Mohawesh, O. (2019): Effect of degradable mulch on tomato growth and yield under field conditions. - Bulgarian Journal of Agricultural Science 25(6): 1122-1132.

[3] Bilck, A. P., Grossmann, M. V. E., Yamashita, F. (2010): Biodegradable mulch films for strawberry production. - Polymer Testing 29(4): 471-476. 
[4] Biswas, S. K., Akanda, A. R., Rahman, M. S., Hossain, M. A. (2015): Effect of drip irrigation and mulching on yield, water-use efficiency and economics of tomato. - Plant Soil and Environment 61(3): 97-102.

[5] Boots, B., Russell, C. W., Green, D. S. (2019): Effects of Microplastics in Soil Ecosystems: Above and Below Ground. - Environ. Sci. Technol 53(19): 11496-11506.

[6] Brodhagen, M., Peyron, M., Miles, C., Inglis, D. A. (2015): Biodegradable plastic agricultural mulches and key features of microbial degradation. - Appl Microbiol Biotechnol 99(3): 1039-1056.

[7] Bu, L. D., Liu, J. L., Zhu, L., Luo, S. S., Chen, X. P., Li, S. Q., Hill, R. L., Zhao, Y. (2013): The effects of mulching on maize growth, yield and water use in a semi-arid region. Agricultural Water Management 123: 71-78.

[8] Chae, Y., An, Y. J. (2018): Current research trends on plastic pollution and ecological impacts on the soil ecosystem: A review. - Environmental Pollution 240: 387-395.

[9] Cosic, M., Stricevic, R., Djurovic, N., Moravcevic, D., Pavlovic, M., Todorovic, M. (2017): Predicting biomass and yield of sweet pepper grown with and without plastic film mulching under different water supply and weather conditions. - Agricultural Water Management 188: 91-100.

[10] Costa, R., Saraiva, A., Carvalho, L. (2014): The use of biodegradable mulch films on strawberry crop in Portugal. - Scientia Horticulturae 173: 65-70.

[11] Cozzolino, E., Giordano, M., Fiorentino, N., El-Nakhel, C., Pannico, A., DiMola, I., Mori, M., Kyriacou, M. C., Colla, G., Rouphael, Y. (2020): Appraisal of Biodegradable Mulching Films and Vegetal-Derived Biostimulant Application as Eco-Sustainable Practices for Enhancing Lettuce Crop Performance and Nutritive Value. - Agronomy 10(3): 427-443.

[12] Deng, L., Yu, Y., Zhang, H. Y., Wang, Q., Yu, R. D. (2019): The Effects of Biodegradable Mulch Film on the Growth, Yield, and Water Use Efficiency of Cotton and Maize in an Arid Region. - Sustainability 11(24): 7039.

[13] Deschamps, S. S., Agehara, S. (2019): Metalized-striped Plastic Mulch Reduces Root-zone Temperatures during Establishment and Increases Early-season Yields of Annual Winter Strawberry. - Hortscience 54(1): 110-116.

[14] Diaz-Perez, J. C. (2009): Root zone temperature, plant growth and yield of broccoli [Brassica oleracea (Plenck) var. italica] as affected by plastic film mulches. - Scientia Horticulturae 123(2): 156-163.

[15] Fawibe, O. O., Hiramatsu, M., Taguchi, Y., Wang, J., Isoda, A. (2020): Grain yield, wateruse efficiency, and physiological characteristics of rice cultivars under drip irrigation with plastic-film-mulch. - Journal of Crop Improvement 34(3): 414-436.

[16] Gu, X. B., Li, Y. N., Du, Y. D. (2017): Biodegradable film mulching improves soil temperature, moisture and seed yield of winter oilseed rape (Brassica napus L.). - Soil \& Tillage Research 171: 42-50.

[17] Hu, H. L. (2015): Studies on Yield Effects, Degradation Properties o Biodegradable Mulch Film and its Field Demonstration. - Zhejiang university, Hang Zhou.

[18] Hu, Q., Li, X. Y., Goncalves, J. M., Shi, H. B., Tian, T., Chen, N. (2020): Effects of residual plastic-film mulch on field corn growth and productivity. - Science of the Total Environment 729: 1-10.

[19] Li, S. X., Wang, Z. H., Li, S. Q., Gao, Y. J., Tian, X. H. (2013): Effect of plastic sheet mulch, wheat straw mulch, and maize growth on water loss by evaporation in dryland areas of China. - Agricultural Water Management 116: 39-49.

[20] Lopez-Tolentino, G., Ibarra-Jimenez, L., Mendez-Prieto, A., Lozano-del Rio, A. J., LiraSaldivar, R. H., Valenzuela-Soto, J. H., Lozano-Cavazos, C. J., Torres-Olivar, V. (2017): Photosynthesis, growth, and fruit yield of cucumber in response to oxo-degradable plastic mulches. - Acta Agriculturae Scandinavica Section B-Soil and Plant Science 67(1): 77-84.

[21] Moreno, M. M., Moreno, A. (2008): Effect of different biodegradable and polyethylene mulches on soil properties and production in a tomato crop. - Scientia Horticulturae 116(3): 256-263. 
[22] Moreno, M. M., Gonzalez-Mora, S., Villena, J., Campos, J. A., Moreno, C. (2017): Deterioration pattern of six biodegradable, potentially low-environmental impact mulches in field condition. - Journal of Environmental Management 200: 490-501.

[23] Namaghi, M. N., Davarynejad, G. H., Ansary, H., Nemati, H., Feyzabady, A. Z. (2018): Effects of mulching on soil temperature and moisture variations, leaf nutrient status, growth and yield of pistachio trees (Pistacia vera L). - Scientia Horticulturae 241: 115-123.

[24] O'Loughlin, J., Finnan, J., McDonnell, K. (2017): Accelerating early growth in miscanthus with the application of plastic mulch film. - Biomass and Bioenergy 100: 52-61.

[25] Sekara, A., Pokluda, R., Cozzolino, E., del Piano, L., Cliciniello, A., Caruso, G. (2019): Plant growth, yield, and fruit quality of tomato affected by biodegradable and nondegradable mulches. - Horticultural Science (Prague) 46(3): 138-145.

[26] Shen, L. X., Wang, P., Zhang, L. L. (2012): Degradation property of degradable film and its effect on soil temperature and moisture and maize growth. - Transactions of the CSAE 28(4): 111-116.

[27] Shen, L. X., Zhang, Y. M., Lan, Y. C., Li, R. F. (2019): Effects of degradable films with different degradation cycles on soil temperature, moisture and maize yield. - Int J Agric \& Biol Eng 12(3): 36-44.

[28] Shi, L., Ao, L. L., Kang, H., Su, H. J. (2012): Evaluation of Biodegradable Films Made of Waste Mycelium and Poly (Vinyl Alcohol) on the Yield of Pak-Choi. - Journal of Polymers and the Environment 20(2): 492-500.

[29] Sintim, H. Y., Bary, A. I., Hayes, D. G., Wadsworth, L. C., Anunciado, M. B., English, M. E., Bandopadhyay, S., Schaeffer, S. M., DeBruyn, J. M., Miles, C. A., Reganold, J. P., Flury, M. (2020): In situ degradation of biodegradable plastic mulch films in compost and agricultural soils. - Science of the Total Environment 727: 138668.

[30] Subrahmaniyan, K., Zhou, W. J. (2008): Soil Temperature Associated with Degradable, Non-Degradable Plastic and Organic Mulches and Their Effect on Biomass Production, Enzyme Activities and Seed Yield of Winter Rapeseed (Brassica napus L.). - Journal of Sustainable Agriculture 32(4): 611-627.

[31] Sun, T., Li, G., Ning, T. Y., Zhang, Z. M., Mi, Q. H., Lal, R. (2018): Suitability of mulching with biodegradable film to moderate soil temperature and moisture and to increase photosynthesis and yield in peanut. - Agricultural Water Management 208: 214-223.

[32] Towa, J. J., Guo, X. P., Zhen, B. (2013): Effects of water management and mulching on weed control and rice grain yield under water saving irrigation. - Journal of Food Agriculture \& Environment 11(1): 538-544.

[33] Yang, Y. J., Huang, Z. B., Yan, Y. M. (2010): Effects on Temperature and Moisture of Soil and Seeding of Maize to Biodegradable Film Coverage. - Journal of Agro-Environment Science 29(S1): 10-14.

[34] Yin, G. H., Tong, N., Hao, L., Liu, Z. X. (2012): Effects of mulching with film of different materials on soil temperature and photosynthesis of peanut leaf. - Agricultural Research in the Arid Areas 30(6): 44-49.

[35] Yin, M. H., Li, Y. N., Fang, H., Chen, P. P. (2019): Biodegradable mulching film with an optimum degradation rate improves soil environment and enhances maize growth. Agricultural Water Management 216: 127-137.

[36] Zhang, J. (2010): Influences of environmental friendly covering materials on soil condition and the response of corn growth. - Northwest A\&F University, Yang Ling.

[37] Zhang, N., Li, Q., Hou, Z. A., Ye, J. (2016): Effect of Polylactic Acid-Degradable Film Mulch on Soil Temperature and Cotton Yield. - Journal of Agricultural Resources and Environment 33(2): 114-119.

[38] Zhang, X. Y., You, S. Y., Tian, Y. Q., Li, J. S. (2019a): Comparison of plastic film, biodegradable paper and bio-based film mulching for summer tomato production: Soil properties, plant growth, fruit yield and fruit quality. - Scientia Horticulturae 249: 38-48. 
[39] Zhang, H., Miles, C., Ghimire, S., Benedict, C., Zasada, I., Devetter, L. (2019b): Polyethylene and biodegradable plastic mulches improve growth, yield, and weed management in floricane red raspberry. - Scientia Horticulturae 250: 371-379.

[40] Zhang, H., Miles, C. (2020): Plastic Mulches Improved Plant Growth and Suppressed Weeds in Late Summerplanted Floricane-fruiting Raspberry. - Hortscience 55(4): 565-572.

[41] Zhang, W. W., Wang, L. H., Zhou, J. Q., Zhu, K. L., Sun, S. J. (2020): Degradability of biodegradable plastic films and its mulching effects on soil temperature and maize yield in northeastern China. - Int J Agric \& Biol Eng 13(2): 146-153. 